J. Clin. Chem. Clin Biochem.

Vol. 15, 1977, pp. 329-331

\title{
A Simplified Micromethod for the Determination of the Acetylator Phenotype
}

\author{
By Joe-Jie Hoo, Laila Hussein, and H. Werner Goedde
}

Institute of Human Genetics (Head: Prof. Dr. H. W. Goedde), University of Hamburg

(Received October 15, 1976/January 7, 1977)

Summary: A simplified and rapid method is described for phenotyping of sulfamethazine acetylation. Two hours after a test dose of sulfamethazine, free and total sulfamethazine are estimated in blood drawn either by capillary or venipuncture. The present method offers sharp segregation between slow and rapid acetylators, requires micro blood volumes drawn from finger- or ear pucture, and is more convenient for population genetics survey as well as for clinical investigations.

\section{Eine vereinfachte Mikromethode zur Bestimmung des Acetylator-Phänotyps}

Zusammenfassung: Eine verfeinerte Schnellmethode zur Phänotypisierung der Sulfamethazin-Acetylierung wird beschrieben. Schon 2 Stunden nach Belastung mit Sulfamethazin läßt sich freies und acetyliertes Sulfamethazin in geringem Volumen von Kapillar- oder Venenblut bestimmen. Die Differenzierung in Langsam- und Schnellacetylierer ist befriedigend. Die Methode erscheint besonders geeignet für genetische Felduntersuchungen und Bestimmungen in der Klinik.

Acetylation is one of the principle pathways for the metabolism of foreign arylamines in most mammalian species. The genetic polymorphism of isoniazid acetylation in man (rapid or slow acetylator) is one of the few established pharmacogenetic phenomena $(1-3)$. It has been shown that the isoniazid acetylator phenotype is congruent with the acetylator phenotype of several structurally unrelated drugs, such as sulfamethazine (4), sulfapyridine (6), and presumably with serotonin (3) and dapsone (7). Recently Weber \& Brenner (8) introduced a simple method for determining the acetylator phenotype, using sulfamethazine $(10 \mathrm{mg} / \mathrm{kg}$ body weight) as substrate (4). Four and a half hours after its oral application, venous blood or urine was collected. The amount of $0.1 \mathrm{ml}$ was dropped on filter paper and dried at room temperature. By addition of trichloroacetic acid the free acetylated sulfamethazine could be dissolved again. The solution was then divided into two portions, one portion was treated further with $4 \mathrm{~mol} / 1$ $\mathrm{HCl}$ and boiled for one hour, the other portion was kept at room temperature. The boiling in acidic environment causes the deacetylation of acetylated sulfamethazine. The total and free sulfamethazine of both portions were estimated by diazotization according to Bratton-Marshall (9). Consequently, the percentage of acetylation could be calculated. For the purpose of population genetic studies we tried to simplify and shorten the procedure, and to avoid the venipuncture which is difficult to deal with in certain countries or diseases, e. g. in psychiatric patients.

\section{Material, Method and Results}

The method of Weber \& Brenner (8) was tested intensively in our laboratory, and it was used to study whole families. The percentage of acetylation obtained from blood specimens gave very satisfactory, reproducible results with blood sampled on different occasions. The acetylation rate of 0.40 could be used to differentiate the rapid (more than 0.40 ) from the slow (less than 0.40 ) acetylator types. However, the acetylation rates obtained from urine specimens were widely overlapping, and were therefore unreliable for phenotyping purposes.

Forty members of our institute, whose acetylator phenotypes were determined by other isoniazid measuring methods $(10,11)$ joined the multiple studies described below and served as controls.

Finger puncture and ear puncture versus venipuncture Venous blood was collected with an heparinized syringe. The capillary blood obtained from finger and ear puncture was collected with either an heparinized micro blood ollecting tube $\left.(0.2 \mathrm{ml})^{1}\right)$ or an heparinized micro hematocrit capillary tube $\left.(0.05 \mathrm{ml})^{2}\right)$ or a $0.1 \mathrm{ml}$ micropipette ${ }^{3}$ ).

The blood samples for the experiments with changing parameters were collected in the above mentioned ways (i. e. veni, finger or ear puncture).

1) Yankee Natelson Micro Blood Collecting Tubes.

2) CAPILETS micro Hematocrit Capillary Tubes.

3) Brand Mikro Pipetten, $100 \mu \mathrm{l}$. 
It became evident that no deviation of results between the different methods of blood sampling was to be noticed. The acetylation rates obtained from finger or ear puncture were in the same range as those obtained by venipuncture.

\section{Storage and samples}

First of all it was proved that the blood sample measured directly or after elution from the filter paper did not show any difference in the final results. Further, the heparinized and dried blood samples (on filter paper) were stored at room temperature, in the refrigerator $\left(4^{\circ} \mathrm{C}\right)$ or on dried ice $\left(-20^{\circ} \mathrm{C}\right)$.

The sterile heparinized blood samples and the dried blood samples maintained their original acetylation percentage after as long as 21 days of storage, even at room temperature. This means that refrigeration is unnecessary during storage, which is especially convenient for transportation between countries. Moreover, the method of drying blood samples on filter paper is preferable, since it is convenient for transport purposes, and sterility precautions are unnecessary.

\section{Time between oral application of sulfamethazine and blood} sample collection

Six individuals were selected for this study. Their acetylation type was first assessed with the isoniazid test. The concentration of isozianid was determined 2,4 and 5 hours after an oral test dose of $3 \mathrm{mg} / \mathrm{kg}$ body weight by the colorimetric method of Eidus \& Harnanansingh (8). The isoniazid concentration in the serum (mg/l) was plotted against time on semi-logarithmic paper, and the half life was computed. Individuals with half lives of $78 \pm 14.5(n=6$; range $60-105)$ minutes were classified as rapid inactivators. Slow acetylators had mean half lives of $228 \pm 38.18$ minutes.

On other occasions blood was sampled $1 \frac{1}{2}, 2,4 \frac{1}{2}$ and 6 hours after oral ingestion of sulfamethazine.

Figure 1 illustrates the acetylation rate of sulfamethazine in their blood as a function of time. A distinct separation of the acetylation rate was apparent after 2 hours.

Testing with higher oral doses of sulfamethazine up to $30 \mathrm{mg} / \mathrm{kg}$ body weight, failed to show clear cut differentiation of phenotypes, when the blood samples were taken less than 2 hours after sulfamethazine ingestion.

Based on the acetylation rate with isoniazid, the rate of 0.20 could be considered as the demarcation between the rapid and slow acetylator types, in blood samples taken 2 hours after a loading test with sulfamethazine. From the results of this study we standardized the method as follows:

1. Oral application of sulfamethazine $(10 \mathrm{mg} / \mathrm{kg}$ 'body weight) after overnight fasting; no food intake before blood sampling.

2. Two hours later capillary blood is collected by finger puncture, ear puncture or heel puncture.

3. At least 3 aliquots (each $0.1 \mathrm{ml}$ ) are dropped on filter paper (Whatman No. 3) and dried at room temperature.

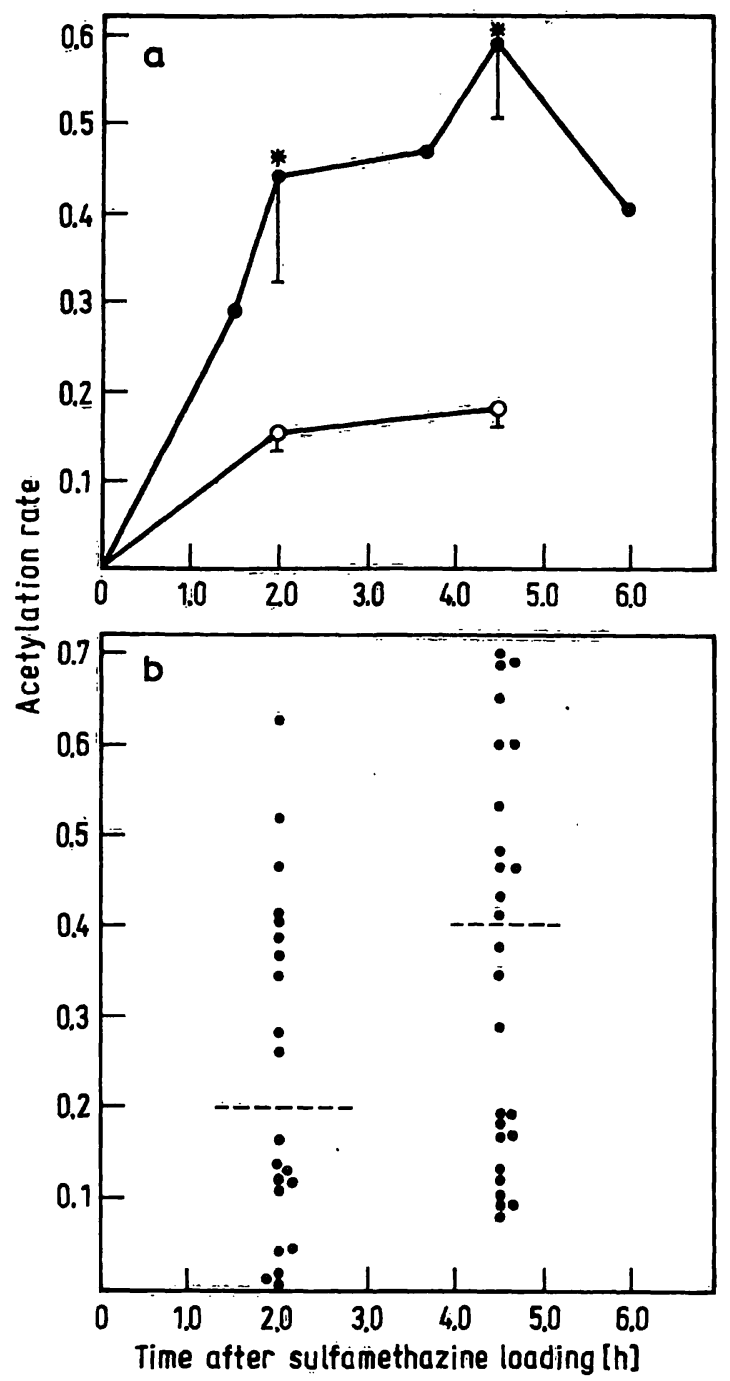

Fig. 1. a) Time course for the acetylation rate of sulfamethazine in blood after an oral dose of $10 \mathrm{mg} / \mathrm{kg}$ body weight in slow and rapid acetylators of isoniazid. Each point represents the mean of 6 normal subjects. Vertical bars represent the standard deviation.

* denotes $\mathrm{p}<0.01$ between blood specimen collected at similar times after the sulfamethazine loading test from slow and rapid acetylators.

b) The distribution of slow and fast acetylators in two populations according to the acetylation rate of sulfamethazine in blood at 2 and $4 \frac{1}{2}$ hours.

4. The subsequent analysis is carried out according to the method described by Weber \& Brenner (8).

5 . The acetylator phenotype is determined according to the mean result of three determinations, acetylation rate above 0.20 being the rapid, below 0.20 the slow type.

\section{Discussion}

The use of filter paper methods provides a convenient technique for safe transportation and storage of the blood sample. The detêrmination of acetylator phenotypes is no longer restricted to the site of testing. After taking the blood sample and drying it on filter paper, 
the sample can be mailed easily to the laboratory where the test is performed. The method described above proved to be very useful and convenient for the purpose of large population genetic studies (12).

As the dosage of sulfamethazine ( $10 \mathrm{mg} / \mathrm{kg}$ body weight) is low, no side effect is to be expected, except for people with sulfadrug hypersensitivity. It is recommended that the acetylator phenotype of the patient should be determined before isoniazid therapy is started.

In the case of the slow type, pyridoxine should be added in the therapy to prevent the onset of peripheral neuritis. The increasing number of reports about cases with isoniazid induced hepatitis or liver necrosis, even in children (13), also justifies the determination of the acetylator phenotype before starting the isoniazid therapy. The studies of Mitchell et al. $(14,15)$ which revealed the rapid acetylators to be more susceptible to liver damage, evoke the need of further investigations of the nature of this polymorphism in man.

\section{Acknowledgement}

We thank Mrs. Gudrun Kriese for skillful technical assistance.

\section{References}

1. Evans, D. A. P., Manley, K. \& McKusick, V. A. (1960), Brit. Med. J. II, 485-491.

2. Goedde, H. W., Schoepf, E. \& Fleischmann, D. (1964), Biochem. Pharmacol. 13, 1671-1675.

3. Goedde, H. W., Altland, K. \& Schloot, W. (1968), Ann. N. Y. Acad. Sci. 151, 742-752.

4. Evans, D. A. P. (1969), J. Med. Genet. 6, 405-407.

5. White, T. A. \& Evans, D. A. P. (1968), Clin. Pharmacol. Therap. 9, 80-88.

6. Schroeder, H. \& Evans, D. A. P. (1972), J. Med. Genet. $9,168-171$.

7. Ellard, G. A., Gammon, P. T., Helmy, H. S. \& Rees, R. J. (1972), Nature 239, 159.

8. Weber, W. W. \& Brenner, W. (1974), Am. J. Hum. Genet. 26, 467-473.

9. Bratton, A. C. \& Marshall, E. K. (1939), J. BioL Chem. $128,537-550$.

10. Goedde, H. W., Schloot, W. \& Benkmann, H. G. (1967), Chemotherapia 12, 61-67.

11. Eidus, L. \& Harnanansingh, A. (1971), Clin. Chem. 17, 492-494.

12. Goedde, H. W., Flatz, G., Rahimi, A. E., Kaifie, S., Kriese, G., Benkmann, H. G. \& Delbrück, H. (1977), Hum. Hered. in press.

13. Vanderhoof, J. A. \& Ament, M. E. (1975), J. Pediatrics $88,867-868$.

14. Mitchell, J. R., Long, M. W., Thorgeirsson, U. P. \& Jollow, D. J. (1975), Chest 68, 181 .

15. Mitchell, J. R., Thorgeirsson, U. P., Block, M., Trimbell, J. A., Snodgrass, W. R., Potter, W. Z., Jollow, D. J. \& Kaiser, H. R. (1975a), Clin. Pharmacol. Ther. 18, 70.

Prof. Dr. H. W. Goedde Institute of Human Genetics University of Hamburg Butenfeld 32

D-2000 Hamburg 54 
